\title{
Facebook as a Platform of Social Interactions for Meaningful Learning
}

\author{
https://doi.org/10.3991/ijet.v14.i04.9363 \\ Nurul Farhana Jumaat ${ }^{(凶)}$, Noriesah Ahmad, Norazrena Abu Samah, \\ Zakiah Mohamad Ashari, Dayana Farzeeha Ali, Abdul Halim Abdullah \\ Universiti Teknologi Malaysia, Malaysia \\ nfarhana@utm.my
}

\begin{abstract}
Undeniably, Facebook has become a significant part of students' life in the 21 st century. Therefore, interactions between instructors and students play a major role in learning through an online social learning environment like Facebook. Such an interaction is known as the key elements that can measure students' learning process, particularly in an online learning environment. Past researchers have agreed that a social networking site does not only promote social interaction but also have high potential to be used for teaching and learning purposes. However, interactions that occur in social networking sites are meaningless due to lack of proper guidance. Lack of proper guidance will lead to no or little intellectual growth among students because the students might be very likely to discuss unrelated topics. Therefore, the goal of this study is to discuss the social interactions that exist in Facebook and its potential as a platform to enhance meaningful learning among students.
\end{abstract}

Keywords-Facebook, social interactions, meaningful learning, online social learning environment.

\section{Introduction}

The social networking sites exist concurrent with the inclination of university students towards learning in an online environment. Social networking sites (SNS) such as Facebook has proven to be attractive to students in high school, college, and university because the platform brings orientation towards self-presentation, the viewing of other's personal information, and multiple means of communication [1]. Facebook is a social networking site that has grown rapidly in popularity in recent years and is often conceived as a space for exchanging thoughts and opinion among students. As one of the member-based internet communities, Facebook allows users to communicate with each other in innovative ways, such as by sending public or private online messages or by sharing photos online [2]. Recently, Facebook has been widely used for educational purpose.

Facebook is the most popular social networking tool among university students, with the users' age ranging between 17 and 61 years [3]. In one study conducted among students [4], it was found that all of them have a Facebook account thus 
indicating that Facebook is the students' most preferred account. The services offered by Facebook are free of charge and the users can connect with each other within their network at no cost. Also, most social networking sites including Facebook provide multiple services, such as instant messaging, blogging, photo-sharing, emailing, and chatting services. All of these services allow students to interact easily with each other. Using Facebook for educational purpose has also brought a number of benefits. As indicated by Selwyn [1], peer interactions can enhance the experience of informal learning. Students can also instantly obtain new information about their academic contents from other students or teachers. Furthermore, Facebook can be one of the teaching methodologies that can be used by instructors to boost the teaching and learning process [5].

According to Santos et al. [6], social networking sites have the potential to support a teaching-and-learning session because they complement the activities in traditional and online classrooms. Another study [7] has shown that students can benefit from a social network site in various ways, such as by integrating it with class activities or by sharing information about the activities they are engaged in. In one study the participants were found to be able to contribute to discussions on Facebook by using fewer clicks compared to when they were using a virtual learning environment (VLE) [8]. A social networking site such as Facebook was also found to be able to promote informal dialogues and knowledge sharing among students [6]. According to [9], social networking tools have the potential to support innovative pedagogical practices and various styles of learning. For instance, the Facebook site has become a platform for students and teachers to be connected. This connection allows them to communicate and share their thoughts, emotions, facts, and opinions without feeling hesitant and shy towards others because the communications take place virtually. This tool is an alternative to students who cannot attend their class physically and regularly due to time and space constraints. [10].

In a social learning environment like Facebook, interaction plays a key element that can measure a student's learning process. A learning process can occur interchangeably from both outside and inside of a classroom with the participation of members in a learning environment through Facebook [10]. Although Facebook allows interactions between members in a learning environment, the conversations that take place can be ineffective because students may prone to discuss unrelated topics, particularly without the guidance from instructors or skillful peers. One study [11] found that less monitoring from mentor had garnered minimum number of replies and comments from participants. To excite further discussion, instructors need to design an interaction and understand their role in the discussion [12], An instructor acts as a cheerleader who encourages his or her students to delve into the materials given. The instructor cum administrator of a Facebook group therefore needs a post that clarifies the discussion because lack of intonation may lead to misunderstanding and arguments among students [8].

Clear and good interaction among members is vital in learning through a Facebook group. An interaction that occurs systematically may lead to meaningful learning, and meaningful learning is needed to enhance students' academic performance and 
achievements. Therefore, this study intends to discuss the educational potential of Facebook as a platform of social interaction for meaningful learning.

\section{$2 \quad$ Literature Review}

\subsection{Meaningful learning}

As stated by Novak [13], useful knowledge and constructions of new knowledge are essentials in meaningful learning. He stated that meaningful learning is the basis to human constructivism. The combination of meaningful contents, course instructors, and peers are significant in fostering meaning learning experience in students' interaction [14].

The main challenge faced by instructors is how to construct an online discussion that contributes to meaningful learning. One study [15] proposed three guidelines that can enhance meaningful learning in online discussion, which are:

- Facilitator's guidelines

- Evaluation rubrics

- Posting of protocol items

Facilitator's guideline can expand a discussion thread in an online discussion. An evaluation rubric is an item that contributes to the weight of examination grade and was proven to be an effective means that can encourage students to discuss and elaborate a particular content. Posting protocols items, however, should not restrict the length of students' posts in a discussion.

\subsection{Social interactions}

Social interactions include all styles of social relations including

- Visiting

- Doing activities together

- Having a communications whether on phone, face to face, online, email, Short Message Service (SMS), or fax [16].

Finding from the same study [16] also revealed the evolvement of information communication technology (ICT) towards engaging social relations among people in various distances. Social networking sites (SNS) such as Facebook is one of the new forms of ICT. One study revealed that social interaction that occurs in a social networking environment might bring strong student engagement; students would give response to their friends' works, share various resources, post questions, and discuss particular topics [17]. The study also stated that a social networking environment is a place where students develop and form social connections in an online group discussion, including a forum. 
In conclusion, the social networking environment including that of Facebook can be beneficial to students. Facebook is a place where interactions occur without any restrictions. Members of Facebook can interact freely. The huge number of Facebook usage among university students has prompted many researches to study the integration of Facebook for academic purposes. The following section will discuss further the use of Facebook for academic purpose.

\subsection{Facebook for academic purposes}

Using Facebook for academic purpose, whether formally or informally, may lead to positive affect to students. Interactions that occur among students and instructors can provide opportunities for students to increase their knowledge. An academic discussion through Facebook can prompt field instructors or lecturers to understand the interest of their students hence provide opportunity for them to demonstrate their intellect [2]. Another scholar [5] found that Facebook had brought positive effect in regard to fulfilling educational purposes. Additional interactions that occur in Facebook particularly through discussion indicates that students get better engagement and understanding about the content of their course materials compared to those who participated less in a Facebook discussion [18]. Another study revealed that most of the students used Facebook to transfer knowledge [19]. As shown in Table 1, majority of the students $(60.4 \%)$ used the social media to share knowledge. Only $2 \%$ of the students were not using the social media for knowledge transfer.

Table 1. Knowledge Transfer through Facebook

\begin{tabular}{|l|c|}
\hline \multicolumn{1}{|c|}{ Knowledge Transfer } & Percentage (\%) \\
\hline Always & 60.4 \\
\hline Usually & 18.3 \\
\hline Often & 17.8 \\
\hline Occasionally & 1.5 \\
\hline Seldom & 2 \\
\hline
\end{tabular}

Source: Suebsom (2015).

As concluded by a previous researcher [10], this kind of technology tends to reach learners extensively. Students who are not active in class due to shyness or other reasons can participate actively in this space. In another study, it was found that integrating education into Facebook might disturb a student's learning process yet they would be alert about their assignment when their friends post about the matter in a discussion space such as a Facebook group [8]. The same study found that most of the students agreed that a Facebook group is suitable for revision purposes because the discussion in the group can match all learning styles. Accordingly, the study presented the following three guidelines on using Facebook for educational purpose:

- A policy is needed to prevent misuse of a Facebook group

- Consistency in which few groups is needed or needs to be created for all courses offered by an institution

- Staffs or instructors need to be consistently involved in a Facebook group 
A policy created in a Facebook group may confine students to discussing only related topics. However, the protocol created should not limit the length of students' posting because such a limitation will give a negative impact to the discussion [15]. Furthermore, institutions need to create multiple Facebook groups in order to make a Facebook group discussion as one of their learning tools. The consistent involvement of staff members such as instructors and lecturers in a Facebook group may also increase students' interactions in the learning platform.

To increase the effectiveness of using a Facebook group for educational purpose, two interactions are considered as crucial factors: student-student interaction and student-instructor interaction. Building interactions are essentials in an online learning environment [20]. There are three key of interaction in an online learning environment [20;21]:

- Student-student interaction

- Student-instructor interaction

- Student-content interaction

Student-student interaction or peer interactions is an interaction that occurs among students. This is one of the key factors to successful online learning. As reported in one study [20], a high-level interaction among students contributed to interactive, meaningful discussion, large number of participation, and longer responses. Communication between students allowed them to share learning experiences [21]. In terms of effect to individual, such interaction can form students' perception that they are part of a community thus helping them to increase their understanding on particular topic [22]. According to [21], interactions between students can create social presences, which in turn, support and maintain their cognitive development. Another study [23] found five elements that can create interactions among students, which are

- Introductions

- Collaborative group project

- Sharing of personal experiences

- Class discussions

- Exchange of resources

In addition, one study [24] concluded that to encourage students to interact with each other requires elements such as the sharing of learning experiences, a sense of community, and teamwork building. Facebook offers some of these features that can contribute to the interaction; for example, users will receive notifications when their friends interact or post on the site [25].

Student-instructor interaction is a communication that occurs between students and instructors. Social interaction between students and instructors exist when an instructor applies strategies to build interpersonal encouragement [26]. One study reported a strong relationship between the level of student-instructor interaction and the level of student's satisfaction with their courses and level of learning [20]. This kind of interaction is crucial in an online learning because it can predict a student's 
level of achievement in his or her learning [27]. Another study revealed that students used Facebook continuously because by using the site, they can discuss, communicate, and interact with peers easily [28]. The benefits of interaction on Facebook to students have been summarized as follows [10]:

- Allowing informal learning in informal communication

- Encouraging collaboration

- Encouraging response or feedback on thoughts

- Collaboration that can occur not in a specific space and time

As to the instructors, they can benefit from the following:

- Getting response or feedback from students

- Continuous communication with students

- Creating instructional strategies for their customers effectively

This interaction occurs between learners generally and the content in the learning space. According to [23], an appropriate design of content can increase a sense of community in an online learning space.

The user-friendliness of an interface can:

- Enhance the motivation for students to learn

- Assist good interaction between students and instructors

\subsection{Instructors' responsibility on Facebook}

Besides maintaining a fun, honest, and clear interaction, instructors need to use various learning strategies that are appropriate to their students [10]. One of the instructor's roles is to make the interactions smooth and give necessary guidance to students [28].To initiate students' interaction on Facebook, an instructor can post a topic for the students to discuss, or he or she can insert a video as in icebreaker along with study questions [30]. Sher's [24] study recommends that an instructor supports his or her students to participate actively by:

- Giving feedback to students

- Serving them as individuals

In another study, Sarapin \& Morris [31] found that instructors who communicated socially on Facebook managed to increase their students' academic performance and satisfaction. Facebook promotes a two-way communication, in which an instructor can give feedback to students, and in turn, encourages students to maintain their participation in a Facebook group [28].

Instructors are responsible to make students interact with each other to yield meaningful learning experience [14]. One study revealed that an instructor can give expectations about class materials, student projects, and assignments, which enables knowledge to be shared beyond physical classroom [29]. Instructors should stress on interactions that occur in a Facebook discussion. There is a need for applications of 
guidelines that can initiate and expand students' interactions towards meaningful learning. Therefore, beside applications policy and full use of Facebook, interaction plays an important role in meaningful learning.

\section{Conclusion}

Interactions among students and students-instructors are vital towards meaningful learning. Interaction that occurs without any guideline or purpose may lead to little intellectual growth among students. As described, many studies have designed interaction as an effort to engage students and enhance their learning through Facebook. As the main motivators in engaging students, instructors need to understand their role and design appropriate interactions in Facebook group towards meaningful learning.

\section{$4 \quad$ References}

[1] Selwyn, N. (2009). Faceworking: exploring students' education-related use of Facebook. Learning, Media and Technology, 34:2(June 2009,), 157-174. http://doi:10.1080/17 439880902923622

[2] Pempek, T. A., Yermolayeva, Y. A., \& Calvert, S. L. (2009). College students' social networking experiences on Facebook. Journal of Applied Developmental Psychology, 30(3), 227-238. http://doi:10.1016/j.appdev.2008.12.010

[3] Junco. R (2012). Too much face and not enough books: The relationship between multiple indices of Facebook use and academic performance. Computers in Human Behavior, 28(1), 187-198.

[4] Jumaat, N. F., \& Tasir, Z. (2016). A framework of metacognitive scaffolding in learning authoring system through Facebook. Journal of Educational Computing Research, 54 (5), 619-659. http://doi:10.1177/0735633115627824

[5] Jumaat, N. F., \& Tasir, Z. (2016). Facebook as a platform for academic-related discussion and its impact on student's success. 4th International Conference on Information and Communication Technology, ICoICT 2016, 19 September 2016. http://doi: 10.1109/ICoICT.2016.7571964

[6] Santos, I. M., Hammond, M., Durli, Z., \& Chou, S.-Y. (2009). Is there a role for social networking sites in education? In A. Tatnall \& A. Jones (Eds.), IFIP Advances in Information and Communication Technology Education and Technology for a Better World (pp. 321-330). Boston: Springer.

[7] Oradini, F., \& Saunders, G. (2008). The use of social networking by students and staff in higher education. Paper presented at the iLearning Forum, Paris.

[8] Menzies, R., Petrie, K., \& Zarb, M. (2015). A case study of Facebook use: Outlining a multi-layer strategy for higher education. Education and Information Technologies. http://doi:10.1007/s10639-015-9436-y

[9] Lucas, M. \& Moreira, A. (2009). Bridging formal and informal learning: a case study on student's perception on the use of social networking tool. Proceedings of the 4th European Conference on Technology Enhanced Learning (EC-TEL 2009), (pp. 325-337). Berlin Springer-Verlag. 
[10] Ractham, P., \& Firpo, D. (2011). Using social networking technology to enhance learning in higher education: a case study using facebook. 2011 44th Hawaii International Conference on System Sciences, 1-10. http://doi:10.1109/HICSS.2011.479

[11] Angeli, C., Valanides, N., \& Bonk, C. J. (2003). Communication in a web-based conferencing system:the quality of computer-mediated interactions. British Journal of Educational Technology, 34(1), 31-44.

[12] Palloff, R., \& Pratt, K. (1999). Building learning communities in cyberspace: effective strategies for the online classroom. San Francisco: Jossey-Bass.

[13] Novak, J. D. (1990). Concept maps and Vee diagrams: two metacognitive tools to facilitate meaningful learning. Instructional Science, 19(1), 29-52.

[14] Yoon, S. (2003). In search of meaningful online learning experiences. New Directions for Adult and Continuing Education, 2003(100), 19-30. doi:10.1002/ace.116

[15] Gilbert, P. K., \& Dabbagh, N. (2005). How to structure online discussions for meaningful discourse: a case study. British Journal of Educational Technology, 36(1), 5-18.

[16] Van Den Berg, P. E. W., Arentze, T. a., \& Timmermans, H. J. P. (2012). New ICTs and social interaction: Modelling communication frequency and communication mode choice. New Media \& Society, 14(6), 987-1003. http://doi:10.1177/1461444812437518

[17] Lu, J., \& Churchill, D. (2012). The effect of social interaction on learning engagement in a social networking environment. Interactive Learning Environments, 22(4), 401-417. http://doi:10.1080/10494820.2012.680966

[18] Dyson, B., Vickers, K., Turtle, J., Cowan, S., \& Tassone, A. (2014). Evaluating the use of Facebook to increase student engagement and understanding in lecture-based classes. Higher Education, 69(2), 303-313. http://doi:10.1007/s10734-014-9776-3

[19] Suebsom, K. (2015). Measuring knowledge transfer through Facebook of higher education classroom. International Journal of Information and Education Technology, 5(6), 437-441. http://doi:10.7763/IJIET.2015.V5.545

[20] Swan, K. (2010). Building learning communities in online courses: the importance of interaction. Education, Communication \& Information, 2(1), 23-49. http://doi:10.1080/ 1463631022000005016

[21] Livengood, K., \& Casarez, L. (2015). All for one and one for all! Collaboration in online learning environments. In Global Learn 2015 (pp. 410-414).

[22] Johnson, Z. S., Cascio, R., \& Massiah, C. a. (2014). Explaining student interaction and satisfaction: an empirical investigation of delivery mode influence. Marketing Education Review, 24(3), 227-238. http://doi:10.2753/MER1052-8008240304

[23] Shackelford, J. L., \& Maxwell, M. (2012). Sense of community in graduate online education: contribution of learner to learner interaction. The International Review of Research in Open and Distributed Learning, 13(4), 228-249.

[24] Sher, A. (2009). Assessing the relationship of student-instructor and student-student interaction to student learning and satisfaction in Web-based Online Learning Environment. Journal of Interactive Online Learning, 8(2), 102-120.

[25] Deschryver, M., Koehler, M., \& Francis, A. P. (2009). Moodle vs. Facebook : Does using Facebook for discussions in an online course enhance perceived social presence and student interaction? In Society for Information Technology \& Teacher Education International Conference, 2009(1), 329-336.

[26] Jung, I., Choi, S., Lim, C., \& Leem, J. (2002). Effects of different types of interaction on learning achievement, satisfaction and participation in web-based instruction. Innovations in Education and Teaching International, 39(2), 153-162. http://doi:10.1080/ $\underline{14703290252934603}$ 
[27] Kang, M., \& Im, T. (2013). Factors of learner-instructor interaction which predict perceived learning outcomes in online learning environment. Journal of Computer Assisted Learning, 29(3), 292-301. http://doi:10.1111/jcal.12005

[28] Shih-Ming Pi, C.-H. C. (2015). The effectiveness of Facebook groups for e-learning. International Journal of Information and Education Technology, 5(7), 477-482. http://doi:10.7763/IJIET.2015.V5.553

[29] Wang, J., Lin, C.-F. C., \& Wei-Chieh Wayne Yu. (2013). Meaningful engagement in Facebook learning environments: Merging Social and Academic Lives. Turkish Online Journal of Distance Education, 14(January), 302-322.

[30] Munoz, C. \& Towner, T. (2009). Opening Facebook: How to use Facebook in the college classroom. In I. Gibson, R. Weber, K. McFerrin, R. Carlsen \& D. Willis (Eds.), Proceedings of SITE 2009--Society for Information Technology \& Teacher Education International Conference (pp. 2623-2627). Charleston, SC, USA: Association for the Advancement of Computing in Education (AACE). Retrieved July 9, 2018 from https://www.learntechlib.org/primary/p/31031/

[31] Sarapin, S. P. \& L. Morris, P. L. (2015). Faculty and Facebook friending: Instructorstudent online social communication from the professor's perspective. The Internet and HigherEducation,, 27, 14-23. http://doi:10.1016/j.iheduc.2015.04.001

\section{Authors}

Nurul Farhana Jumaat is a lecturer at School of Education, Faculty of Social Sciences and Humanities at University Teknologi Malaysia.

Noriesah Ahmad is a postgraduate student at School of Education, Universiti Teknologi Malaysia.

Norazrena Abu Samah is a lecturer at School of Education, Faculty of Social Sciences and Humanities, at Universiti Teknologi Malaysia.

Zakiah Mohamad Ashari is a lecturer at School of Education, Faculty of Social Sciences and Humanities, at Universiti Teknologi Malaysia.

Dayana Farzeeha Ali is a lecturer at School of Education, Faculty of Social Sciences and Humanities, at Universiti Teknologi Malaysia.

Abdul Halim Abdullah is a lecturer at School of Education, Faculty of Social Sciences and Humanities, at Universiti Teknologi Malaysia.

Article submitted 07 August 2018. Resubmitted 24 October 2018. Final acceptance 14 January 2018. Final version published as submitted by the authors. 